\title{
Uma visão histórica sobre uma epidemia contemporânea: a Aids e o caso peruano
}

\author{
A historical overview of a contemporary epidemic: \\ Aids and the case of Peru \\ Simone Monteiro \\ Pesquisadora e chefe do Laboratório de Educação Ambiental e em Saúde (LEAS) do \\ Departamento de Biologia, Instituto Oswaldo Cruz \\ Av. Brasil, 4365 \\ 21045-900 — Rio de Janeiro — RJ Brasil
}

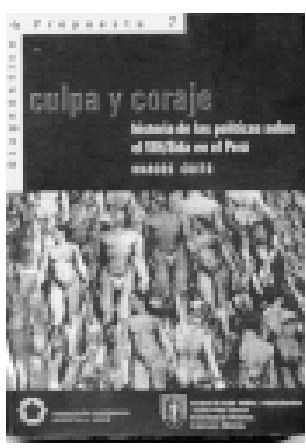

Marcos Cueto Culpa e coragem, bistoria das politicas sobre VIH/Sida em Peru, Lima. Consorcio de Investigación Económicay Social, Facultad de Salud Pública y Administración, Universidad Peruana Cayetano Herendia, 2001
A análise histórica das políticas sobre HIV/Aids no Peru, desenvolvida no livro de Marcos Cueto, representa mais um importante esforço para a compreensão das repercussões sociais de uma epidemia contemporânea que se caracterizou por apresentar um agente etiológico desconhecido, desafiar os sofisticados tratamentos médicos científicos do século XX e não ter cura.

Uma primeira contribuição importante do livro do historiador referese à possibilidade de conhecermos aspectos de uma das sociedades que integra a América Latina, aspectos estes nem sempre explorados nas reflexões desenvolvidas no Brasil no campo das ciências sociais e da saúde. Tendo em vista que os primeiros casos identificados de Aids datam do início da década de 1980, uma outra qualidade relevante do livro em questão está na utilização de uma perspectiva histórica acerca de uma epidemia contemporânea.

Ao analisar a origem e o desenvolvimento das políticas públicas e dos estudos médicos voltados para o diagnóstico e controle da epidemia de HIV/Aids na realidade peruana, o autor nos brinda com uma clara e bem fundamentada cronologia dos fatos, dos contextos nacional e internacional e dos atores envolvidos nas respostas frente a um novo agravo à saúde. O não aprofundamento de temas caros a esse tipo de reflexão - como a visão e as experiências das pessoas vivendo com HIV/Aids e a história da sexualidade no Peru - é justificado e não compromete a reflexão proposta.

Ao longo do livro compreende-se de que maneira os sérios problemas de ordem política, social e econômica do país, somados aos estigmas atribuídos à Aids, repercutiram nas respostas sociais e na definição das políticas oficiais de identificação e controle da epidemia durante o período de 1983 a 2000; e quais as suas implicações em termos sociais, políticos e epidemiológicos. Dentro dessa perspectiva identificam-se, por um lado, os questionamentos sobre a prioridade de enfrentamento da Aids frente aos demais agravos de saúde pública e às mazelas experimentadas pela população peruana. Por outro lado, percebe-se a influência do discurso científico biomédico sobre a nova síndrome e o impacto de instituições intergovernamentais, como a Organização Mundial de Saúde (OMS) e a Organização Pan-Americana de Saúde (OPAS), nas iniciativas associadas ao controle da epidemia.

Além da riqueza das variadas fontes e do cuidado na fundamentação dos argumentos desenvolvidos, chamam a atenção no livro de Marcos 
Cueto as semelhanças e peculiaridades entre a dinâmica da epidemia de HIV/Aids no Peru e em outras realidades, dentro e fora da América Latina. Em termos de proximidade, identifica-se o papel dos meios de comunicação de massa na divulgação e interpretação dos acontecimentos, colaborando para a construção de uma visão fatalista em torno da epidemia. Outro aspecto comum, vinculado às vias de transmissão do vírus da Aids, diz respeito às atitudes de discriminação frente a homens que fazem sexo com homens e profissionais do sexo - atitudes decorrentes de traços culturais associados às relações de gênero e à definição da identidade sexual —, presentes na reação de profissionais de saúde e nos discursos médico e pedagógico sobre moral e sexualidade.

Em termos epidemiológicos, embora o Brasil se destaque pelo número expressivo de casos, quando comparado aos demais países da América Latina, e apresente particularidades regionais no que se refere à distribuição de casos, há tendências gerais similares em relação ao contexto do Peru. Ilustra esse ponto de vista a identificação do predomínio de casos de HIV/Aids entre homossexuais no período inicial da epidemia e as alterações ao longo dos anos, caracterizadas pelo maior controle da qualidade do sangue e hemoderivados, bem como pelo aumento do número de casos entre as populações empobrecidas e os heterossexuais. Vale destacar que o fenômeno da heterossexualização da epidemia se vincula ao aumento da vulnerabilidade das mulheres ao HIV, conhecido como o fenômeno da feminização da epidemia e, conseqüentemente, ao crescimento de casos via transmissão vertical (de mãe para filho).

As peculiaridades do caso peruano em relação às respostas sociais à epidemia de HIV/Aids ficam mais evidentes por meio da descrição e análise de três fases históricas. A primeira etapa da história das políticas de HIV/Aids descrita pelo autor compreende os anos de 1983 a 1987. Essa fase foi caracterizada pela abordagem fatalista dos meios de comunicação sobre a nova epidemia e pela divulgação dos primeiros estudos acadêmicos da área biomédica sobre a Aids no Peru, sobretudo realizados por um reconhecido imunologista, Raúl Patruco.

Apoiado no conhecimento da literatura especializada e na autoridade do discurso científico, coube a Patruco atestar (ou melhor, autenticar) a presença de casos de Aids no país e informar acerca do diagnóstico e dos meios de transmissão do HIV, estimulando novas investigações sobre o tema na realidade peruana - também assinaladas por Cueto. Os estudos revelaram que os primeiros casos de Aids ocorrem entre homossexuais que haviam retornado ao país após terem vivido, no exterior, em locais de alta incidência de casos.

Ainda no mesmo período, no âmbito governamental, destaca-se a criação de comissões oficiais (1985) e de um programa de Estado (1987) voltados para o estudo do problema do HIV/Aids. Tais iniciativas foram marcadas pela ênfase na dimensão biológica da epidemia, percebida como um fenômeno eminentemente "médico, científico, inesperado y de alcance limitado" (p. 54), não sendo considerado uma prioridade da saúde pública. Com relação à participação dos demais atores sociais nessa fase histórica, Cueto chama a atenção para 
a escassez de vozes da sociedade civil organizada na contraposição dessa perspectiva reducionista; assim como para o importante papel de um moderno laboratório da marinha americana, ${ }^{1}$ o Namir, que se tornou o laboratório nacional de referência para o HIV por um determinado período. Os estudos do Namir sobre a prevalência do vírus da Aids no Peru geraram reformulações no controle dos bancos de sangue do país e contribuíram para a capacitação de profissionais da saúde na área de biossegurança, indicando a possibilidade de apropriação local de projetos de saúde de origem externa.

A segunda parte das respostas sociais, correspondente aos anos de 1988 a 1995, teve como marco a criação do Programa Especial de Control del Sida (Pecos), apoiado por financiamentos externos e diferenciado dos demais programas do Ministério da Saúde. Considerando o agravamento da crise econômica e social do país, e a diminuição de recursos e apoio político às ações do Estado, deve-se salientar o impacto da influência da OMS e da OPAS na definição de políticas oficiais. Isso ocorreu particularmente, no Peru, por meio do incentivo à criação de programas nacionais especializados e à promoção de investigações, publicações e conferências sobre a epidemia de Aids.

Nessa fase surgiram os primeiros ativistas e voluntários que participavam de movimentos da sociedade civil, que se organizavam para promover a melhoria da assistência às pessoas soropositivas. As organizações nãogovernamentais promoveram discussões sobre os direitos humanos das pessoas com HIV/Aids, a divulgação de informações para diferentes segmentos sociais e estudos relevantes sobre a dinâmica da epidemia na sociedade peruana. Tais ações acompanhavam-se de embates entre a visão governamental e não-governamental, mas também de perspectivas de trabalhos em cooperação. A partir de 1994 ocorreram melhorias na área da vigilância epidemiológica, da assistência às pessoas com HIV/Aids, do aconselhamento e da divulgação do uso de camisinhas, bem como o incremento de pesquisas acadêmicas sobre a epidemia. Essas providências guardam relação com as mudanças na direção do Pecos, com o apoio de agências internacionais e com a incorporação de profissionais oriundos do movimento social na esfera pública.

A terceira e última parte das reações à epidemia apresentada pelo historiador começa em 1996, com o início do Programa de Control de Enfermedades de Transmisión Sexual y Sida (Procetss), e vai até os anos recentes (2000). Nessa etapa há conquistas relevantes, expressas por: investimentos de recursos públicos nas ações de controle da epidemia; regulamentação de normas voltadas para a uniformização dos princípios e critérios de funcionamento das instituições públicas e privadas constitutivas da área da saúde; promulgação da lei que responsabilizava o Ministério da Saúde pela elaboração de um plano nacional de luta contra o HIV e as demais doenças sexualmente transmissíveis. Ocorrem também importantes vitórias políticas, como o estabelecimento de leis punitivas para atitudes discriminatórias, a obrigatoriedade do aconselhamento (e difusão de procedimentos para

\footnotetext{
${ }^{1}$ Presente em outros países, tal estrutura sugere que a disseminação mundial da Aids era um assunto de segurança nacional para os militares norte-americanos.
} 
tanto) antes e após o teste e a proteção da confidencialidade do diagnóstico.

Outro passo significativo dessa fase refere-se ao incremento da interação e cooperação entre o âmbito governamental e nãogovernamental e as instituições acadêmicas, e a edição de boletins informativos do Proctess, criando-se oportunidades para divulgar as atividades do programa e rever expressões e conceitos inadequados, como grupo de risco, aidético (sidoso), entre outros. Verifica-se uma maior atenção à capacitação de profissionais na área de DST. Entra também em foco o aumento da compreensão das particularidades da visão de mundo e das práticas sexuais de segmentos populacionais como os jovens e mulheres de diferentes classes sociais - que influenciam a vulnerabilidade ao HIV para além do acesso a informações corretas acerca dos meios de transmissão e prevenção da Aids.

Pondera-se que as mudanças assinaladas foram potencializadas pelo processo de inserção de membros do movimento civil organizado no aparato estatal. Esta 'migração', também presente no caso brasileiro e internacional, tem sido objeto de alguns estudos sobre as peculiaridades da história contemporânea da Aids, com vistas a analisar os aspectos positivos e negativos desse processo no que diz respeito ao comprometimento ou fragilização da força política do movimento social. Além de descrever as conquistas desse período, Marcos Cueto apresenta as críticas ao Procetss, argumenta sobre as implicações do governo autoritário de Alberto Fujimori para a área da saúde e mostra os novos desafios da epidemia de HIV/Aids.

Tendo por base o caminho percorrido por Marcos Cueto sobre as respostas sociais e políticas à Aids na sociedade peruana, podemos vislumbrar as contribuições da história contemporânea de uma epidemia na construção de uma interlocução efetiva entre a pesquisa e a formulação de políticas públicas na área da saúde. Considerando os avanços no controle da epidemia, no âmbito da prevenção, da assistência, dos direitos humanos e em termos da mobilização social, um olhar histórico constitui uma referência fundamental para orientar o enfrentamento dos antigos e novos problemas impostos pela Aids.

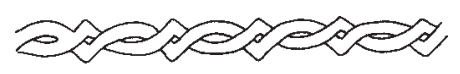

